\title{
TLR2 and AP-1/NF-kappaB are involved in the regulation of MMP-9 elicited by heat killed Listeria monocytogenes in human monocytic THP-1 cells
}

\author{
Puthiyaveetil Kochumon Shihab, Areej Al-Roub, Moneera Al-Ghanim, Anfal Al-Mass, Kazem Behbehani \\ and Rasheed Ahmad ${ }^{*}$
}

\begin{abstract}
Background: MMP-9 is crucial for a normal immune response, but excessive release of this enzyme leads to severe tissue damage. Listeria monocytogenes (LM) is an opportunistic food-borne pathogen causing listerosis, meningitis and sepsis. Heat killed Listeria monocytogenes (HKLM) activates immune system and leads production of cytokines and chemokines. However, nothing is known about the involvement of HKLM in MMP-9 regulation. Therefore we investigated the role of HKLM in the regulation of MMP-9 gene expression in THP-1 cells.
\end{abstract}

Methods: Commercially available heat killed Listeria monocytogenes was used in this study. HKLM-induced MMP-9 expression was assessed with quantitative real-time QPCR and ELISA. Action of HKLM in different signaling pathways were studied by using THP-1-XBlue ${ }^{T M}$ cells (THP-1-cells with NF-KB/AP-1 reporter construct), THP-1-XBlue ${ }^{\mathrm{TM}}$-defMyD cells (MyD88 ${ }^{-1-}$ THP-1 cells), anti-TLR2 mAb and pharmacological inhibitors. Phospho and total proteins were determined by Western blotting.

Results: Increased MMP-9 production (mRNA: 395-Fold; Protein: 8141 pg/ml; $P<0.05$ ) was observed in HKLM stimulated THP-1 cells as compared to the un-stimulated THP-1 cells. This production of MMP-9 was completely abrogated by anti-TLR2 blocking mAb $(P=0.0024)$. Furthermore, THP-1-XBlue ${ }^{\text {TM}}$-defMyD cells were unable to produce MMP-9 in response to HKLM. HKLM- induced activation of NF-kappaB/AP-1 was also observed in THP-1-XBlue ${ }^{\mathrm{TM}}$ Cells. In addition, inhibitors of JNK (SP600125), MEK/ERK (U0126; PD98056), p38 MAPK (SB203580) and NF-kappaB (BAY 11-7085, Triptolide and Resveratrol) significantly suppressed $(P<0.05)$ HKLM-stimulated MMP-9 expression.

Conclusion: Our results indicate that HKLM activates TLR2 and NF-KB/AP-1 signaling pathways, leading to up-regulation of MMP-9 production in THP-1 cells. Thus, MMP-9 could be an appropriate therapeutic target to stop severe tissue damage caused by infection or chronic inflammation.

\section{Introduction}

Listeria monocytogenes is a Gram-positive foodborne pathogen that is widely distributed in nature, occurring in soil, water, various food products, animals, and humans [1]. Infection by Listeria monocytogenes occurs almost exclusively after ingestion of contaminated food [2]. Immunocompromised individuals, neonates, pregnant woman, elderly persons, and patients suffering from transplantation events are most susceptible to infections. Listeriosis causes invasive disease including septicemia and meningitis [3]. Although the

\footnotetext{
* Correspondence: rasheed.ahmad@dasmaninstitute.org

Immunology \& Innovative Cell therapy Unit, Dasman Diabetes Institute, Al-Soor Street, P.O. Box 1180, Dasman 15462, Kuwait
}

listeriosis incidence is low, the high mortality rates (about 24\%) due to septicemia and meningitis make L. monocytogenes one of the most deadly human food-borne pathogens [4]. Immediate immune responses are triggered during LM infection. Innate immunity to LM is mediated via toll like receptors or nucleotide-binding oligomerization domain (NOD)-like receptors (NLRs) [5]. Toll-like receptors (TLRs) have been shown to play an important role in the host's innate immune responses to microbial infections through the induction of proinflammatory cytokines, chemokines, and type I interferons by macrophages and dendritic cells $[6,7]$. Member of the TLR family, namely TLR2 has been shown to be critical in the initiation of innate immune responses to LM infection in the mouse model $[8,9]$. Recognition of a 
microbial invasion through the TLRs triggers the activation of signaling pathways, resulting in the recruitment of several adaptor proteins to the TIR domain. However, myeloid differentiation factor 88 (MyD88) is a key adaptor protein which is common to almost all TLRs except TLR3 [10]. MyD88 activates in turn IL-1 receptor-associated kinases (IRAK) family members and tumor necrosis factor-alpha receptor-associated factor 6 (TRAF6) [11,12]. These adaptor proteins have essential role in the activation of NF- $\mathrm{KB}$ and mitogen-activated protein kinase (MAPK) pathways [13-18]. NF-kappaB and AP-1 transcription pathways are involved in the regulation of inflammatory mediators that trigger the migration of the inflammatory cells into the tissue. Inflammatory cells migration into tissues is dependent on several events including adherence to endothelial cells and penetration through the vessel wall into the extracellular matrix [19-21].

Matrix metalloproteinases (MMPs) form a family of zinccontaining proteases that degrade all extracellular matrix components and have an important role in tissue remodeling and immunomodulatory functions [22,23]. As gelatin is a major component of extra- cellular matrix (ECM) and in view of their collagen type IV-specific degradation capacity, MMP-9 plays a key role in ECM breakdown. MMP-9 is predominantly secreted by monocytes which are central cells in developing immune response to infection. The production of MMP- 9 by monocytes is of interest in the context of facilitating leukocyte infiltration into infected sites through degrading type IV collagen in vascular basement membranes [24]. MMP-9 production is tightly controlled at the level of gene transcription and its unrestricted release/ activity may contribute to host tissue damage during infection. Elevated levels of MMP-9 were found in different inflammatory and infectious diseases [25-28]. MMP-9 gene expression in monocytic cells is regulated by different cytokines, including TNF-alpha IL-1beta, IL-18 and microbial components [29-31].

Previous work has shown that Heat killed listeria monocytogenes (HKLM) activates immune system by regulating the expression of cytokines (IL-1 $\beta$, IL-6, IL-8, IL-12 and TNF $\alpha$ and chemokines [32-34]. However, nothing is known about the regulation of MMP-9 by HKLM in monocytic cells. In this study we therefore looked at the influence of HKLM on monocyte production of MMP-9. We show that HKLM induces MMP-9 in the monocytic cell line THP-1 via activation of MAPK and NF-kappaB. MMP-9 secretion was blocked by neutralizing TLR2. MyD88-/- cells abrogate the HKLM stimulated MMP-9 secretion.

\section{Materials and methods}

\section{Cell culture and stimulation}

Human monocytic leukemia cell line THP-1 was purchased from American Type Culture Collection (ATCC) and grown in RPMI-1640 culture medium (Gibco, Life Technologies, Grand Island, USA) supplemented with 10\% fetal bovine serum (Gibco, Life Technologies, Grand Island, NY, USA), $2 \mathrm{mM}$ glutamine (Gibco, Invitrogen, Grand Island, NY, USA), $1 \mathrm{mM}$ sodium pyruvate, $10 \mathrm{mM}$ HEPES, 100ug/ml Normocin $50 \mathrm{U} / \mathrm{ml}$ penicillin and $50 \mu \mathrm{g} / \mathrm{ml}$ streptomycin (P/S; (Gibco, Invitrogen, Grand Island, NY, USA), and incubation at $37^{\circ} \mathrm{C}$ (with humidity) in $5 \% \mathrm{CO}_{2}$. THP-1-XBlue cells stably expressing a secreted embryonic alkaline phosphatase (SEAP) reporter inducible by NF-kB and AP-1 were purchased from InvivoGen (InvivoGen, San Diego, CA, USA). THP-1-XBlue cells show similar response to HKLM purchased from InvivoGen, (San Diego, CA, USA) as THP-1 cells. All the experiments were performed with THP-1-XBlue cells at a cell density of $1 \times 10^{6} / \mathrm{ml}$ in 12-well plates. THP-1-XBlue ${ }^{\mathrm{mu}}$-defMyD cells (cells deficient in MyD88 activity; MyD88-/- THP-1 cells) were also purchased from InvivoGen (InvivoGen, San Diego, CA, USA). THP-1-XBlue cells were cultured in complete RPMI medium with the addition of zeocin $(200 \mu \mathrm{g} / \mathrm{ml})$ (InvivoGen, San Diego, CA, USA) to select for cells expressing the SEAP -NF-kB/AP-1 reporter. THP-1-XBlue ${ }^{\text {rx }}$-defMyD cells were cultured in complete RPMI medium with the addition of Zeocin $(200 \mathrm{ug} / \mathrm{ml})$ and HygroGold (100ug/ml) (InvivoGen, San Diego, CA, USA).

Prior to stimulation, THP-1 cells were transferred into normal medium and plated in 12-well plates (Costar, Corning Incorporated, Corning, NY, USA) at $1 \times 10^{6}$ cells/well cell density unless indicated otherwise. In dose-response experiment, the following HKLM concentrations were used to stimulate THP- 1 cells: $1-9 \times 10^{7}$ particles $/ \mathrm{ml}$. In subsequent experiments, the optimal (non-cytotoxic) concentration of HKLM $\left(3 \times 10^{7}\right.$ particles $\left./ \mathrm{ml}\right)$ or TNF-alpha $(25 \mathrm{ng} / \mathrm{ml})$ were used to stimulate cells for $24 \mathrm{hr}$ at $37^{\circ} \mathrm{C}$. Cells were harvested for RNA isolation and conditioned media were collected for measuring MMP-9 secretion levels and SEAP activity. Conditioned media were collected and stored at $-80^{\circ} \mathrm{C}$.

\section{Quantification of NF-KB/AP-1 activity}

THP-1 XBlue cells (InvivoGen, San Diego, CA) are THP-1 cells stably transfected with a reporter construct, expressing a secreted embryonic alkaline phosphatase (SEAP) gene under the control of a promoter inducible by the transcription factors NF- $\mathrm{kB}$ and AP-1. Upon stimulation, NF- $\mathrm{kB}$ and AP-1 are activated and subsequently the secretion of SEAP is promoted. Levels of SEAP were detected in the conditioned media after $4 \mathrm{hr}$ incubation of supernatants with Quanti-Blue medium (InvivoGen, San Diego, CA, USA) at $650 \mathrm{~nm}$ wave length by ELISA reader.

\section{Real time quantitative RT-PCR}

Total RNA was extracted using RNeasy Mini Kit (Qiagen, Valencia. CA, USA). The cDNA was synthesized using 
$1 \mu \mathrm{g}$ of total RNA using high capacity cDNA reverse transcription kit (Applied Biosystems, Foster city, CA, USA). 50 ng cDNA was used in each real-time PCR reaction. For real-time polymerase chain reaction (PCR), complementary DNA was amplified with Inventoried TaqMan Gene Expression Assay products (MMP-9: Hs00234579_m1; GAPDH: Hs03929097_g1) containing two gene-specific primers and one TaqMan MGB probe (6-FAM dye-labeled) using a Taq$\mathrm{Man}^{\circ}$ Gene Expression Master Mix (Applied Biosystems, Foster city, CA, USA) in a 7500 Fast Real-Time PCR System (Applied Biosystems, Foster City, CA, USA). The mRNA levels were normalized against GAPDH mRNA and the amounts of MMP-9 mRNA relative to control were calculated with $\Delta \Delta$ Ct-method [35]. Relative mRNA expression was expressed as fold expression over average of control gene expression. The expression level in control treatment was assumed to be 1 . Values are presented as mean \pm SEM. Results were analyzed statistically; $P<0.05$ was considered significant.

\section{ELISA for secreted MMP-9 and TIMP-1 in cell culture supernatants}

Concentrations of MMP-9 and TIMP-1 in cell culture supernatants were measured using sandwich ELISA according to the manufacturer's instructions (R\&D systems, Minneapolis, USA).

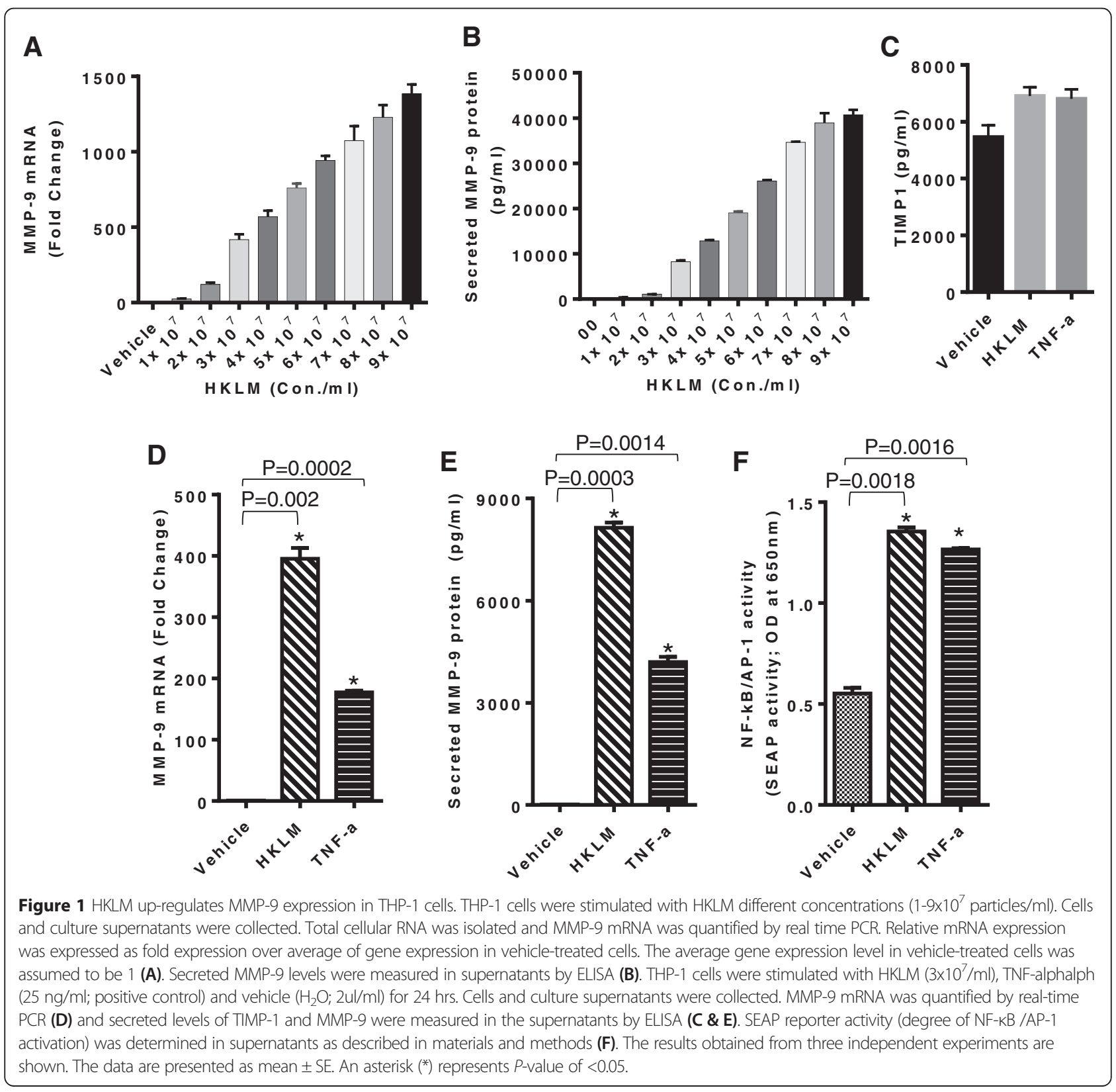




\section{Western blotting}

Cellular lysates were prepared as described previously $[7,36]$. Briefly THP-1 cells were incubated for $30 \mathrm{~min}$ with lysis buffer (Tris $62.5 \mathrm{mM}$ (pH 7.5), 1\% Triton X-100, 10\% glycerol). The lysates were then centrifuged at $14000 \mathrm{rpm}$ for $10 \mathrm{~min}$ and the supernatants were collected. Protein concentration in the lysates was measured by Quickstart Bradford Dye Reagent, 1x Protein Assay kit (BioRad Laboratories, Inc, CA). Protein $(20 \mu \mathrm{g})$ samples were mixed with sample loading buffer, heated for $5 \mathrm{~min}$ at $95^{\circ} \mathrm{C}$ and were resolved on SDS-12\% SDS-PAGE and transferred to immobilon polyvinyldifluoride (PVDF) membranes (BioRad Laboratories, USA) by electro blotting. The blots were blocked with $5 \%$ non-fat milk in PBS at room temperature and then probed with rabbit anti-human antibodies against p-MEK1/2, pERK1/2, p-JNK, p-p38, pc-jun, $\mathrm{p}-\mathrm{IKK} \alpha / \beta, \mathrm{p}-\mathrm{IKB}, \mathrm{p}-\mathrm{NF}-\mathrm{kappaB}$ and Beta Actin in 1:1000 dilution at $4^{\circ} \mathrm{C}$ overnight. All the primary antibodies were purchased from Cell Signalling (Cell Signalling Technology, Inc). The blots were then washed three times with TBS and incubated for $2 \mathrm{~h}$ with HRPconjugated secondary antibody (Promega, Madison, WI, USA). Immunoreactive bands were developed using an Amersham ECL Plus Western Blotting Detection System (GE Health Care, Buckinghamshire, UK) and visualized by Molecular Imager ${ }^{\circledR}$ VersaDoc $^{\mathrm{Tm}}$ MP Imaging Systems (BioRad Laboratories, Hercules, CA, USA).

\section{Statistical analysis}

Statsitical analysis was performed using GraphPad Prism software (La Jolla, CA, USA). Data are shown as mean \pm standard deviation values, unless otherwise indicated. Unpaired Student t-test was used to compare means between groups. In all cases, $P$ value $<0.05$ was considered significant.

\section{Results}

HKLM induces MMP-9 production in THP-1 cells

It has been reported that heat killed listeria monocytogenes (HKLM) triggers the production of inflammatory mediators [32-34,37]. However, MMP-9 induction by HKLM has yet not been studied in monocytic cells. To determine whether HKLM up-regulates MMP-9 gene expression, THP-1 cells were treated with different concentrations of HKLM for 24 hrs. Cells and conditioned media were harvested. MMP-9 gene and protein expression were induced in THP-1 cells in a dose-dependent manner (Figure 1A \& B, respectively). We further found that HKLM concentration of $3 \times 10^{7}$ particles/ml did not induce changes in cellular morphology and viability; therefore, this concentration was used in all subsequent experiments. In addition, we also confirmed that the production of TIMP-1 protein differed non-significantly between vehicle and HKLM (Figure 1C). MMP-9 gene

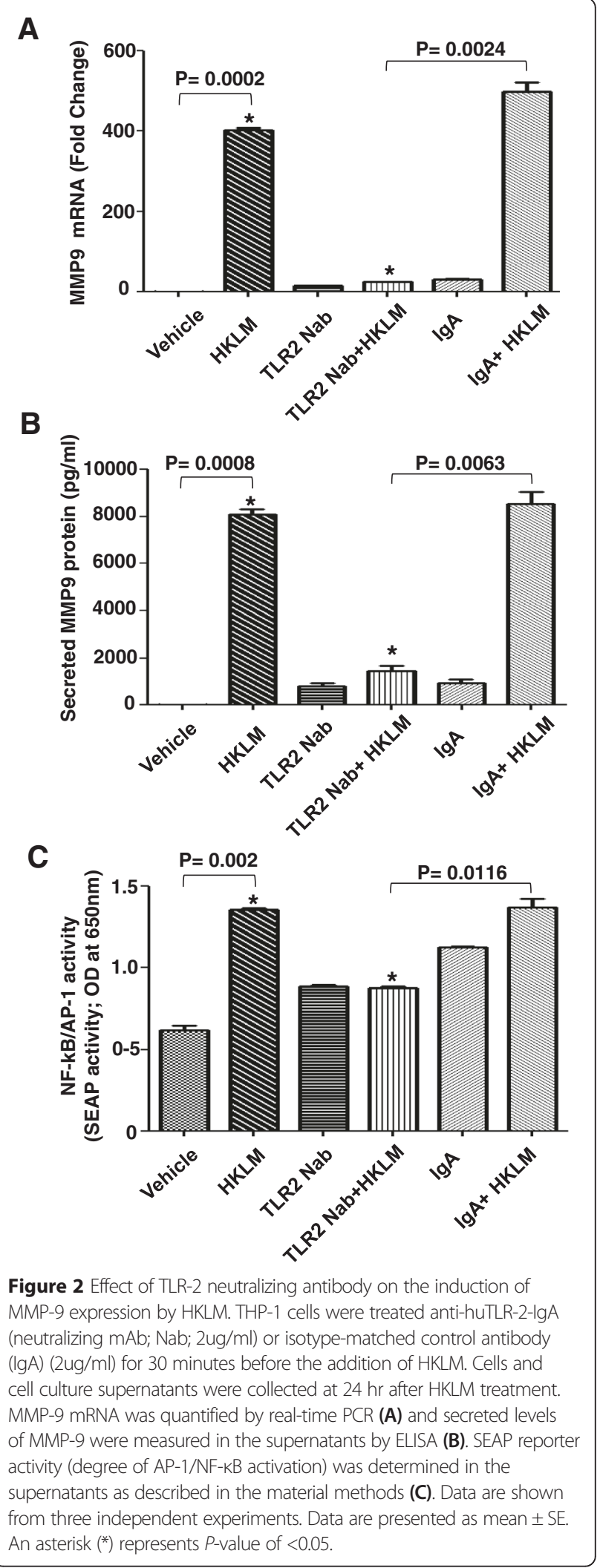


expression was increased at both mRNA (395 Fold; $\mathrm{P}=$ $0.002)$ and protein levels $(8141 \pm 215 \mathrm{pg} / \mathrm{ml} ; \mathrm{P}=0.003)$ in THP-1 cells treated with HKLM as compared to the un-stimulated THP-1 cells. MMP-9 protein expression induced by TNF-alpha $(4195 \pm 157 \mathrm{pg} / \mathrm{ml} ; \mathrm{P}=0.0014)$ as positive control (Figure 1D \& E).

Studies have revealed an essential role of NF-kappaB and AP-1 activation in MMP-9 secretion in different cell types by several external stimuli $[38,39]$. To investigate the involvement of NF-kappaB and AP-1 in HKLM induced MMP-9 gene expression, the THP-1 X-blue cells, expressing a reporter gene SEAP driven by NF-kappaB and AP-1 response elements, were treated with HKLM or TNF-alpha. Elevated SEAP activity (NF-kappaB/AP-1 activation; $\mathrm{P}=0.0018)$ was determined in the condition media obtained from THP-1 cells treated with HKLM as compared to unstimulated cells (Figure 1F).

Involvement of TLR2 in HKLM induced MMP-9 production Previous studies have shown that TLR2 can interact with several ligands including listeria monocytogenes [40]. Therefore, we hypothesized that the TLR2 signaling pathway might be involved in HKLM-induced MMP-9 production. To test this hypothesis, THP-1 cells were treated with anti-TLR2-neutralizing monoclonal antibody (a-TLR2 mAb) or a control isotype (IgA) for $30 \mathrm{~min}$. The cells were then treated with HKLM and evaluated for MMP-9 gene expression. Neutralization of TLR2, with an anti-TLR2 mAb markedly reduced HKLM-induced MMP-9 gene up-regulation in THP-1 cells (Figure $2 \mathrm{~A}$ and $\mathrm{B} ; \mathrm{P}<0.05)$. In this condition, MMP-9 gene expression levels were similar to those seen in non-treated cells, whereas there was no change in MMP-9 expression in cells treated with the control isotype antibody. Furthermore, consistent with the observed effect of neutralization of TLR2 on the induction of MMP-9, HKLM -induced NF-kB/AP-1 activity was significantly reduced $(\mathrm{P}<0.05)$ in $\mathrm{THP}-1$ cells pretreated with anti TLR2 neutralizing antibody compared with control antibody (Figure 2C). These results reveal the absolute requirement of TLR2-mediated signaling for MMP-9 gene up-regulation by HKLM in THP-1 cells.

\section{Role of MyD88 in HKLM induced MMP-9 production}

We found in earlier experiments that TLR2 is required for HKLM-mediated induction of MMP-9 production in THP-1 cells and that only HKLM interaction with cellular receptor on the target cells was responsible for inducing this effect. MyD88 appears to be a key adaptor protein as it is required for signalling by all TLRs except TLR3 [10]. To investigate the role of MyD88 in regulation of MMP-9 by HKLM, THP-1-XBlue ${ }^{\mathrm{Tm}}$-defMyD cells (MyD88-/-; cells deficient in MyD-88 activity) were incubated with HKLM or TNF-alpha. MyD88 deficiency diminished HKLM-induced MMP gene up-regulation in THP-1 cells at both mRNA and protein levels (Figure 3A and B). In contrast, TNF-alpha induction of MMP-9 was not affected in MyD88-/- cells as it activates MMP-9 gene expression via MyD88-independent pathway. Likewise, MyD-88 deficiency also completely decreased activation of NF-kB/AP-1 following HKLM treatment (Figure $3 \mathrm{C}$ ). These data suggest that MyD88 has important role in the activation of NF-kappaB/ AP-1 transcription factors for the induction of MMP-9 by HKLM.
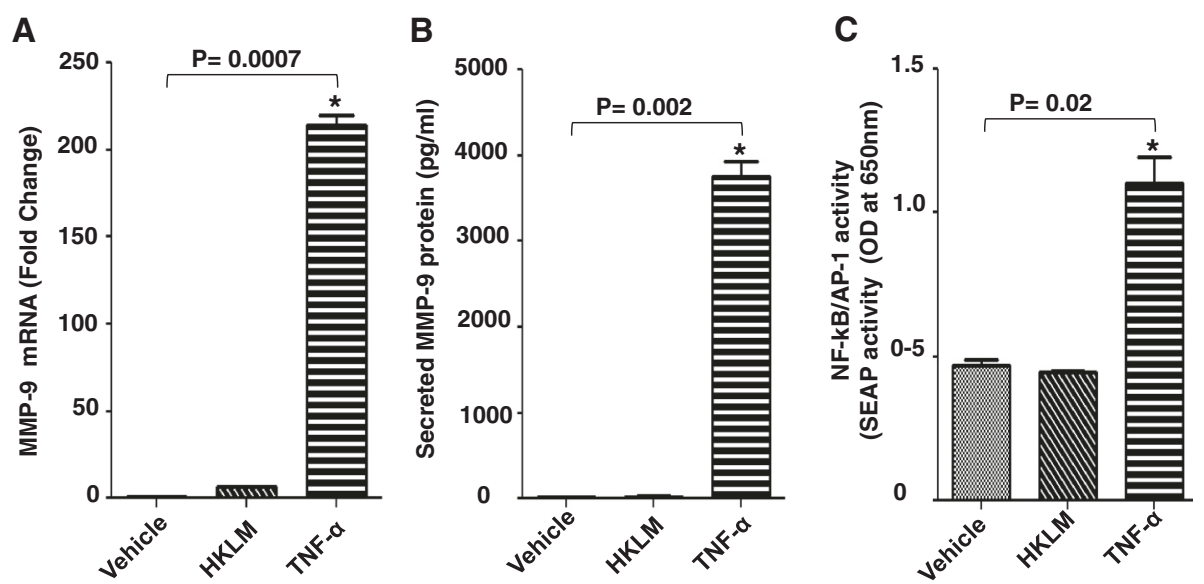

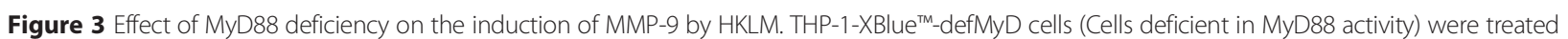
with HKLM $\left(3 \times 10^{7} / \mathrm{ml}\right)$, TNF-alpha $(25 \mathrm{ng} / \mathrm{ml})$ and vehicle (water; $\left.2 \mathrm{ul}\right)$ for $24 \mathrm{hr}$. Cells and supernatants were collected. Cells were used for the isolation of total RNA and MMP-9 gene expression was quantified by real-time PCR (A). Secreted levels of MMP-9 protein were determined in supernatants by ELISA (B). SEAP reporter activity (degree of AP-1/NF-KB activation) was also determined in cell supernatants (C). Data are shown as mean \pm SE. An asterisk (*) represents $P$-value of $<0.05$. 
MAPK and NF-kappaB signaling pathways are involved in HKLM-induced MMP-9 upregulation

Because activation of MEK/ERK and MAPK/JNK signalling pathways have been reported to mediate MMP-9 production $[41,42]$, we next asked whether these molecules play role in HKLM induced MMP-9 production. Figure 4A showed that stimulation of THP-1 cells by HKLM increased phophorylation of MEK/ERK, JNK, p38, c-jun. As expected the Inhibitors of the MAPK pathway (MEK/ERK or p38 or JNK) down-regulate the expression of MMP-9 in THP-1 cells stimulated by HKLM. The expression of MMP-9 mRNA was reduced (Figure 4B; $P<0.05$ ) by treatment with inhibitors of either MAPK/JNK (SB203580/SP600125) or MEK/ERK (PD98059, U0126). Consistent with qRT-PCR results, MMP-9 levels in culture supernatants of THP-1 cells were significantly suppressed $(P<0.05)$ after treatment with inhibitors of either MAPKs or MEK/ERK (Figure 4C). Given that the promoter contains the NF- $\mathrm{B}$ binding site $[43,44]$, the lack of NF- $\mathrm{B}$ B activation is expected to result in the reduced MMP-9 gene expression. Figure 5A showed that stimulation of THP-1 cells by HKLM increased phophorylation of IKK- $\alpha / \beta, p-I k B$ and NF-kappaB. The use of NF- $\kappa$ B inhibitors (BAY 11-7805, Triptolide and Resveratrol), significantly reduced the MMP-9 gene expression $(P<0.0001)$ (Figure 5B and $C)$.

\section{Discussion}

MMP-9 is essential for normal physiological conditions but its increase in production could be involved in the pathogenesis of various diseases such as chronic inflammation, tumor cell metastasis, arthritis, obesity and in

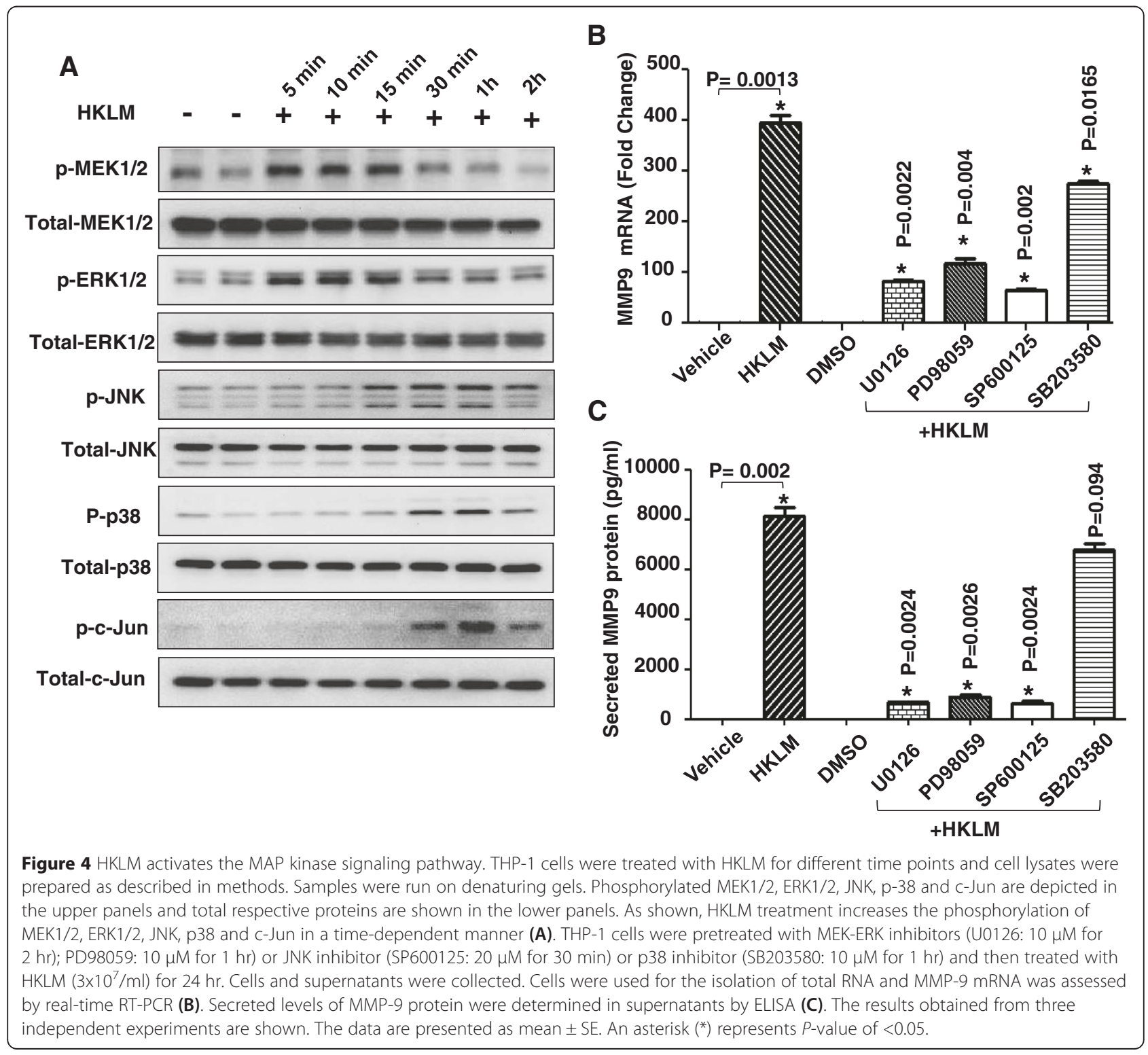




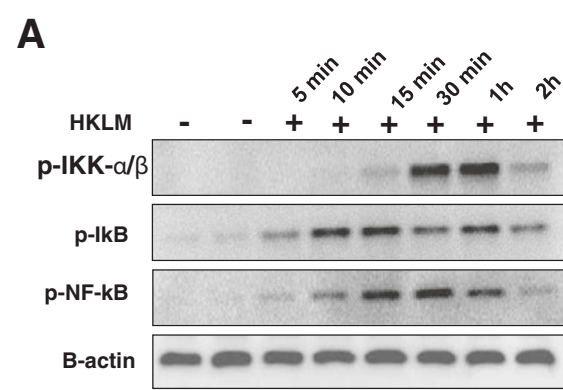

B

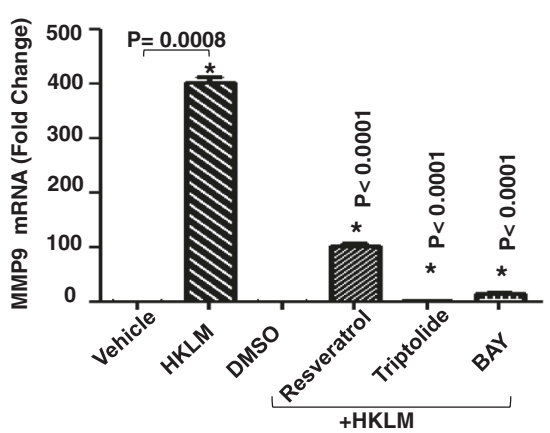

C

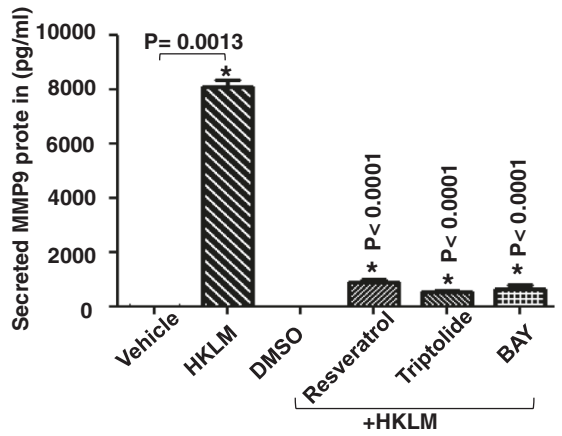

Figure 5 Effect of NF-kappaB pathway inhibitors on MMP-9 induction. THP-1 cells were treated with FSL-1 for different time points and cell lysates were prepared as described in methods. Samples were run on denaturing gels. Phosphorylated IKKa/ $\beta$, IkB, and NF-KB are depicted in the upper panel and B-actin is shown in the bottom panel (A). THP-1 cells were pretreated with NF-kB inhibitors (BAY 11-7085, 10 $\mu$ M; Triptolide, 10 $\mu$ M or Resveratrol, $15 \mathrm{uM})$ for $1 \mathrm{hr}$ and then treated with $\mathrm{HKLM}\left(3 \times 10^{7} / \mathrm{ml}\right)$ for $24 \mathrm{hr}$. Cells and supernatants were collected. Cells were used for the isolation of total RNA and MMP-9 mRNA was assessed by real-time PCR (B). Secreted levels of MMP-9 protein were determined in supernatants by ELISA (C). Data are shown as mean $\pm \mathrm{SE}$. An asterisk $\left(^{*}\right)$ represents $P$-value of $<0.05$.

the progression of various infectious diseases ([25-28]. Also, MMP involvement in the pathogenesis of central nervous system diseases have been reported. A study reported the presence of Listeria monocytogenes antigens and MMP-7/9 in sheep brains [45]. Previously, we studied the MMP-9 production induced by FSL-1, a synthetic lipoprotein derived from Mycoplasma salivarium [46]; whereas in this study, we have demonstrated that MMP-9 was up-regulated in monocytic cells upon exposure to Heat killed Listeria monocytogenes (HKLM). This MMP-9 up-regulation requires TLR2/MyD88dependent activation of NF-kB/AP-1. Our study shows that HKLM mediated induction of MMP-9 in monocytic cells is due to HKLM interaction with surface receptor on the target cells. The interaction of different bacteria with TLRs has been shown to be decisive in the outcome of immune responses and bacterial pathogenesis. For instance, TLR2 serves as the signaling receptor for molecules such as LP, LTA, and PGN. PGN, a cell wall component of gram positive bacteria, induces IL-6 and MMP-9 gene expression in microglia and neurtophils, respectively $9[47,48]$. Other studies have also shown that macrophages from TLR2-deficient mice lost the ability to secrete the inflammatory cytokines TNF-alpha and IL-6 in response to bacterial component from gram-positive bacteria [49], which suggests that interaction of the TLR on the cells with the bacterial component is responsible, in part, to induce immune response in the host. In the present study, to demonstrate that TLR2 participates in the induction of MMP-9 by HKLM, we achieved no cellular responses to the HKLM after neutralization of TLR2 on THP-1 cells. Previous studies have shown that the cytokine production induced by gram positive bacteria in cells of the monocytic linage depends on TLR2 stimulation $[50,51]$.

Recognition of a microbial invasion through the TLRs triggers the recruitment and activation of several adaptor proteins to the TIR domain. MyD88 is a key adaptor protein and is common to almost all TLRs except TLR3 [10]. The involvement of MyD88 is well known in the induction of various inflammatory mediators. Thus, we also suggested that inducing effect of HKLM on MMP-9 was blocked in MyD88 deficient cells. It is noteworthy in this regard that the role of MyD88 has provided a further evidence for the involvement of the TLR2 in this induction of MMP-9. The interaction of MyD88 with the TLR receptor promotes the recruitment of other adaptor proteins that in turn activates downstream kinases including NF- $\mathrm{BB}$-inducing kinase (NIK), IKK $\alpha / \beta / \gamma$, and mitogen-activated protein kinases (MAPKs) [13-18]. In the classical pathway, activated IKK $\beta$ which is part of an $I K K \alpha / \beta / \gamma$ complex, phosphorylates 
IKB $\alpha$ or IKB $\beta$ leading to their proteosomal degradation. As a result, NF- $\mathrm{BB}$ gets activated. In case of TLRs, che classical NF- $\mathrm{kB}$ pathway gets activated. Whereas in case of lymphoid development, the alternate pathway is involved in which NIK activates IKK $\alpha$ which phosphorylates NF-kB2 [52]. These signaling cascades thus activate multiple transcription factors such as NF-kappaB and activator protein 1 (AP-1) [53]. Indeed, previous studies indicate that AP-1 and NF-kappaB have binding sites in the MMP-9 promoter region and play important role in MMP-9 gene regulation [54]. Therefore, we show the involvement of NF-кB/AP-1 activation in HKLM-induced MMP-9 gene expression in THP-1 cells. This is also confirmed by our observations that neutralization of TLR2 and deficiency of MyD88 blocked NF-kB/AP-1 activation along with the inhibition of MMP-9 expression. As NF-kappaB and MAPK pathways have been extensively studied downstream of various inflammatory stimuli. It is well established that stimulation of monocytes/macrophages by microbial components induces phosphorylation of p38, ERK1/2, and c-Jun $\mathrm{NH}_{2}$ terminal kinase (JNK). MAPKs are activated largely by bacterial products through TLRs and participated in the inflammatory response induced by TLR 2 activation in monocytes/macrophages [53,55]. Our results showed that HKLM induced phosphorylation of p38, ERK1/2, and c-Jun $\mathrm{NH}_{2}$-terminal kinase (JNK) are involved in the regulation of MMP-9 gene expression. Moreover, this is confirmed by our findings that HKLM induced MMP-9 was reduced by inhibition of MEK/ERK, JNK and p38. The involvement of MEK/ERK as well as that of other kinases (JNK and p38) in MMP-9 expression has been reported in other cell systems $[54,56]$. Since our data shows that NF-kappaB signaling pathways are also very effective in the regulation MMP-9 along with MAPK signaling pathways. Thus, we established that HKLM induced phosphorylation of the IKK $\alpha / \beta$, IKB and NF-kappaB. Furthermore, we found that effect of HKLM on MMP-9 regulation was suppressed in the cells treated with inhibitors of NF-kappaB signaling pathways. Our results suggested that signaling pathways induced by HKLM that regulate MMP-9 expression in monocytic cells is also dependent on NF-kappaB signalling pathways. Many studies have revealed an essential role of NF-kappaB and AP-1 activation in MMP-9 secretion has been revealed in different cell types by several external stimuli $[38,39]$. A few studies support that NF-kappaB and AP-1 transcription factors are regulated by the similar intracellular signal transduction cascades [57-60]. For example, in the activation of JNK by inflammatory or stress stimuli and the nuclear traslocation of NF-kappaB, the simultaneous activation of NFkappaB and AP-1 suggest that these transcription factors work cooperatively [61]. Another indication of the interaction between AP-1 and NF-kappaB activation pathways comes from the studies showing that the MAPK pathway activation leads to activation of JNK and IkB kinase complexes [62]. This cooperative interaction between AP-1 and NF-kappaB is further supported by the presence of a scaffold protein which was shown to be involved in the activation of JNK pathways and NF-kappaB nuclear translocation [63]. From these studies, taken together, there is possibility that NF-kappaB and AP-1 can modulate the activity of each other.

In summary, we have shown that TLR2 regulates the expression of MMP-9 in THP-1 cells in response to HKLM by multiple cooperative mechanisms. In particular, we have identified HKLM-mediated activation of MAPK, AP-1 and NF- $\mathrm{KB}$ signaling pathways as critical steps for transcriptional up-regulation of MMP-9.

\section{Competing interests}

The authors declare that they have no competing interests.

\section{Authors' contributions}

RA conceived, designed the experiments, analyzed the data, wrote and edited the manuscript. PS performed most of the experiments, analyzed the data and wrote methodology. AA and MG also performed, a part, of the experiments. KB critically revised the manuscript. All authors read and approved the final manuscript.

\section{Acknowledgments}

This study was financially supported by Kuwait Foundation for the Advancement of Sciences (KFAS). We thankfully acknowledge the support by Mr. Azadali K. Moorji and the staff of the Tissue Bank Core Facility.

Received: 27 May 2014 Accepted: 9 March 2015

Published online: 18 April 2015

\section{References}

1. Hamon M, Bierne $H$, Cossart P. Listeria monocytogenes: a multifaceted model. Nat Rev Microbiol. 2006:4:423-34.

2. Swaminathan B, Gerner-Smidt P. The epidemiology of human listeriosis. Microbes Infect. 2007;9:1236-43.

3. Ooi ST, Lorber B. Gastroenteritis due to Listeria monocytogenes. Clin Infect Dis. 2005; $40: 1327-32$.

4. Farber JM, Peterkin PI. Listeria monocytogenes, a food-borne pathogen. Microbiol Rev. 1991;55:476-511.

5. Creagh EM, O'Neill LA. TLRs, NLRs and RLRs: a trinity of pathogen sensors that co-operate in innate immunity. Trends Immunol. 2006;27:352-7.

6. Kawai T, Akira S. Innate immune recognition of viral infection. Nat Immunol. 2006;7:131-7.

7. Ahmad R, El Bassam S, Cordeiro P, Menezes J. Requirement of TLR2mediated signaling for the induction of $\mathrm{IL}-15$ gene expression in human monocytic cells by HSV-1. Blood. 2008;112:2360-8.

8. Cossart P, Mengaud J. Listeria monocytogenes. A model system for the molecular study of intracellular parasitism. Mol Biol Med. 1989;6:463-74.

9. Czuprynski CJ, Brown JF. Effects of purified anti-Lyt-2 mAb treatment on murine listeriosis: comparative roles of Lyt-2+ and L3T4+ cells in resistance to primary and secondary infection, delayed-type hypersensitivity and adoptive transfer of resistance. Immunology. 1990;71:107-12.

10. Kawai T, Akira S. TLR signaling. Cell Death Differ. 2006;13:816-25.

11. Akira S, Takeda K. Toll-like receptor signalling. Nat Rev Immunol. 2004;4:499-511.

12. Takeda K, Kaisho T, Akira S. Toll-like receptors. Annu Rev Immunol. 2003;21:335-76.

13. Cao Z, Xiong J, Takeuchi M, Kurama T, Goeddel DV. TRAF6 is a signal transducer for interleukin-1. Nature. 1996;383:443-6.

14. Barton GM, Medzhitov R. Toll-like receptor signaling pathways. Science. 2003;300:1524-5.

15. Cao Z, Henzel WJ, Gao X. IRAK: a kinase associated with the interleukin-1 receptor. Science. 1996;271:1128-31.

16. Gohda J, Matsumura T, Inoue J. Cutting edge: TNFR-associated factor (TRAF) 6 is essential for MyD88-dependent pathway but not toll/IL-1 receptor 
domain-containing adaptor-inducing IFN-beta (TRIF)-dependent pathway in TLR signaling. J Immunol. 2004;173:2913-7.

17. Hayden MS, West AP, Ghosh S. NF-kappaB and the immune response. Oncogene. 2006;25:6758-80.

18. Gosselin J, Flamand L, D’Addario M, Hiscott J, Menezes J. Infection of peripheral blood mononuclear cells by herpes simplex and Epstein-Barr viruses. Differential induction of interleukin 6 and tumor necrosis factor-alpha. J Clin Invest. 1992;89:1849-56.

19. Adams DH, Lloyd AR. Chemokines: leucocyte recruitment and activation cytokines. Lancet. 1997;349:490-5.

20. Baggiolini M. Chemokines and leukocyte traffic. Nature. 1998;392:565-8.

21. Ebnet $K$, Vestweber D. Molecular mechanisms that control leukocyte extravasation: the selectins and the chemokines. Histochem Cell Biol. 1999;112:1-23.

22. Woessner Jr JF. Matrix metalloproteinases and their inhibitors in connective tissue remodeling. FASEB J. 1991;5:2145-54.

23. Brinckerhoff CE, Matrisian LM. Matrix metalloproteinases: a tail of a frog that became a prince. Nat Rev Mol Cell Biol. 2002;3:207-14.

24. Goetzl EJ, Banda MJ, Leppert D. Matrix metalloproteinases in immunity. J Immunol. 1996;156:1-4

25. Tchetina EV, Demidova NV, Karateev DE, Nasonov EL. Rheumatoid factor positivity is associated with increased joint destruction and upregulation of matrix metalloproteinase 9 and cathepsin $\mathrm{k}$ gene expression in the peripheral blood in rheumatoid arthritic patients treated with methotrexate. Int J Rheumatol. 2013;2013:457876.

26. Medina C, Radomski MW. Role of matrix metalloproteinases in intestinal inflammation. J Pharmacol Exp Ther. 2006;318:933-8.

27. Leifler KS, Svensson S, Abrahamsson A, Bendrik C, Robertson J, Gauldie J, et al. Inflammation induced by MMP-9 enhances tumor regression of experimental breast cancer. J Immunol. 2013;190:4420-30.

28. Okamoto T, Akuta T, Tamura F, van Der Vliet A, Akaike T. Molecular mechanism for activation and regulation of matrix metalloproteinases during bacterial infections and respiratory inflammation. Biol Chem. 2004;385:997-1006.

29. Tsai CL, Chen WC, Lee IT, Chi PL, Cheng SE, Yang CM. C-Src-dependent transactivation of PDGFR contributes to TNF-alpha-induced MMP-9 expression and functional impairment in osteoblasts. Bone. 2014;60:186-97.

30. Lin CC, Kuo CT, Cheng CY, Wu CY, Lee CW, Hsieh HL, et al. IL-1 beta promotes A549 cell migration via MAPKs/AP-1- and NF-kappaB-dependent matrix metalloproteinase-9 expression. Cell Signal. 2009;21:1652-62.

31. Abraham M, Shapiro S, Lahat N, Miller A. The role of IL-18 and IL-12 in the modulation of matrix metalloproteinases and their tissue inhibitors in monocytic cells. Int Immunol. 2002;14:1449-57.

32. Yeung VP, Gieni RS, Umetsu DT, DeKruyff RH. Heat-killed Listeria monocytogenes as an adjuvant converts established murine Th2-dominated immune responses into Th1-dominated responses. J Immunol. 1998;161:4146-52.

33. McKernan DP, Dennison U, Gaszner G, Cryan JF, Dinan TG. Enhanced peripheral toll-like receptor responses in psychosis: further evidence of a pro-inflammatory phenotype. Transl Psychiatry. 2011;1:e36.

34. Miller MA, Skeen MJ, Ziegler HK. Protective immunity to Listeria monocytogenes elicited by immunization with heat-killed Listeria and IL-12. Potential mechanism of IL-12 adjuvanticity. Ann N Y Acad Sci. 1996;797:207-27.

35. Livak KJ, Schmittgen TD. Analysis of relative gene expression data using real-time quantitative PCR and the 2(-Delta Delta C(T)) Method. Methods. 2001;25:402-8.

36. Ahmad R, Sylvester J, Ahmad M, Zafarullah M. Adaptor proteins and Ras synergistically regulate IL-1-induced ADAMTS-4 expression in human chondrocytes. J Immunol. 2009;182:5081-7.

37. Suzaki A, Komine-Aizawa S, Hayakawa S. Suppression of osteoblast toll-like receptor 2 signaling by endothelin-1. J Orthop Res. 2014;32:910-4.

38. Yang CM, Lin CC, Lee IT, Lin YH, Chen WJ, Jou MJ, et al. Japanese encephalitis virus induces matrix metalloproteinase-9 expression via a ROS/ c-Src/PDGFR/PI3K/Akt/MAPKs-dependent AP-1 pathway in rat brain astrocytes. J Neuroinflammation. 2012;9:12.

39. Suh SJ, Kwak CH, Chung TW, Park SJ, Cheeeei M, Park SS, et al. Pimaric acid from Aralia cordata has an inhibitory effect on TNF-alpha-induced MMP-9 production and HASMC migration via down-regulated NF-kappaB and AP-1. Chem Biol Interact. 2012;199:112-9.

40. Lavelle EC, Murphy C, O'Neill LA, Creagh EM. The role of TLRs, NLRs, and RLRs in mucosal innate immunity and homeostasis. Mucosal Immunol. 2010;3:17-28.

41. Liang KC, Lee CW, Lin WN, Lin CC, Wu CB, Luo SF, et al. Interleukin-1beta induces MMP-9 expression via p42/p44 MAPK, p38 MAPK, JNK, and nuclear factor-kappaB signaling pathways in human tracheal smooth muscle cells. J Cell Physiol. 2007:211:759-70
42. Kang MH, Oh SC, Lee HJ, Kang HN, Kim JL, Kim JS, et al. Metastatic function of BMP-2 in gastric cancer cells: the role of PI3K/AKT, MAPK, the NF-kappaB pathway, and MMP-9 expression. Exp Cell Res. 2011;317:1746-62.

43. Bond M, Fabunmi RP, Baker AH, Newby AC. Synergistic upregulation of metalloproteinase- 9 by growth factors and inflammatory cytokines: an absolute requirement for transcription factor NF-kappa B. FEBS Lett. 1998;435:29-34.

44. Himelstein BP, Lee EJ, Sato H, Seiki M, Muschel RJ. Transcriptional activation of the matrix metalloproteinase-9 gene in an H-ras and v-myc transformed rat embryo cell line. Oncogene. 1997;14:1995-8.

45. Ilhan F, Ulusoy Y, Haligur M. Matrix metalloproteinase expression in sheep with listerial meningoencephalitis. Res Vet Sci. 2012;92:269-72.

46. Ahmad R, Shihab PK, Jasem S, Behbehani K. FSL-1 induces MMP-9 production through TLR-2 and NF-kappaB /AP-1 signaling pathways in monocytic THP-1 cells. Cell Physiol Biochem. 2014;34:929-42.

47. Lin HY, Tang CH, Chen JH, Chuang JY, Huang SM, Tan TW, et al. Peptidoglycan induces interleukin-6 expression through the TLR2 receptor, JNK, C-Jun, and AP-1 pathways in microglia. J Cell Physiol. 2011;226:1573-82.

48. Wang M, Myhre AE, Pettersen SJ, Dahle MK, Foster SJ, Thiemermann C, et al. Peptidoglycan of Staphylococcus aureus induces enhanced levels of matrix metalloproteinase-9 in human blood originating from neutrophils. Shock. 2005:24:214-8.

49. Travassos LH, Girardin SE, Philpott DJ, Blanot D, Nahori MA, Werts C, et al. Toll-like receptor 2-dependent bacterial sensing does not occur via peptidoglycan recognition. EMBO Rep. 2004:5:1000-6.

50. Giambartolomei GH, Zwerdling A, Cassataro J, Bruno L, Fossati CA, Philipp MT. Lipoproteins, not lipopolysaccharide, are the key mediators of the proinflammatory response elicited by heat-killed Brucella abortus. J Immunol. 2004;173:4635-42.

51. Scian R, Barrionuevo P, Giambartolomei GH, Fossati CA, Baldi PC, Delpino MV. Granulocyte-macrophage colony-stimulating factor- and tumor necrosis factor alpha-mediated matrix metalloproteinase production by human osteoblasts and monocytes after infection with Brucella abortus. Infect Immun. 2011;79:192-202.

52. Ghosh S, Karin M. Missing pieces in the NF-kappaB puzzle. Cell. 2002;109 Suppl:S81-96.

53. Zhang G, Ghosh S. Toll-like receptor-mediated NF-kappaB activation: a phylogenetically conserved paradigm in innate immunity. J Clin Invest. 2001;107:13-9.

54. Tseng HC, Lee IT, Lin CC, Chi PL, Cheng SE, Shih RH, et al. IL-1beta promotes corneal epithelial cell migration by increasing MMP-9 expression through NF-kappaB- and AP-1-dependent pathways. PLoS One. 2013;8:e57955.

55. Ulevitch RJ, Tobias PS. Receptor-dependent mechanisms of cell stimulation by bacterial endotoxin. Annu Rev Immunol. 1995;13:437-57.

56. Cho HJ, Kang JH, Kwak JY, Lee TS, Lee IS, Park NG, et al. Ascofuranone suppresses PMA-mediated matrix metalloproteinase-9 gene activation through the Ras/Raf/ MEKJERK- and Ap1-dependent mechanisms. Carcinogenesis. 2007;28:1104-10.

57. Abate C, Patel L, Rauscher 3rd FJ, Curran T. Redox regulation of fos and jun DNA-binding activity in vitro. Science. 1990;249:1157-61.

58. Fan H, Sun B, Gu Q, Lafond-Walker A, Cao S, Becker LC. Oxygen radicals trigger activation of NF-kappaB and AP-1 and upregulation of ICAM-1 in reperfused canine heart. Am J Physiol Heart Circ Physiol. 2002;282:H1778-86.

59. Karin M, Takahashi T, Kapahi P, Delhase M, Chen Y, Makris C, et al. Oxidative stress and gene expression: the AP-1 and NF-kappaB connections. Biofactors. 2001;15:87-9.

60. Lee SW, Han SI, Kim HH, Lee ZH. TAK1-dependent activation of AP-1 and c-Jun N-terminal kinase by receptor activator of NF-kappaB. J Biochem Mol Biol. 2002;35:371-6.

61. Verma IM, Stevenson JK, Schwarz EM, Van Antwerp D, Miyamoto S. Rel/NF-kappa B/I kappa B family: intimate tales of association and dissociation. Genes Dev. 1995;9:2723-35.

62. Lee FS, Hagler J, Chen ZJ, Maniatis T. Activation of the IkappaB alpha kinase complex by MEKK1, a kinase of the JNK pathway. Cell. 1997:88:213-22.

63. Tapon N, Nagata K, Lamarche N, Hall A. A new rac target POSH is an SH3containing scaffold protein involved in the JNK and NF-kappaB signalling pathways. EMBO J. 1998;17:1395-404. 